\title{
Magnetic Resonance Imaging Depicted Muscle Injuries in Athletes Participating in the Rio De Janeiro 2016 Summer Paralympic Games
}

\author{
Daichi Hayashi ${ }^{1,2 *}$, Michel D. Crema ${ }^{1,3}$, Mohamed Jarraya ${ }^{4}$, Cheri A. Blauwet ${ }^{5}$, Rafael \\ Heiss $^{6}$, Frank W. Roemer ${ }^{1,6}$, Wayne E. Derman ${ }^{7,9 \#}$ and Ali Guermazi ${ }^{1,8 \#}$ \\ ${ }^{1}$ Quantitative Imaging Center, Department of Radiology, Boston University School of Medicine, USA

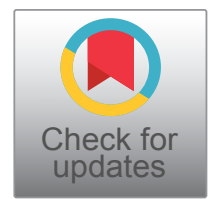

${ }^{2}$ Department of Radiology, Stony Brook Medicine, State University of New York, USA

${ }^{3}$ Institute of Sports Imaging, Department of Sports Medicine, French National Institute of Sports (INSEP), France

${ }^{4}$ Department of Radiology, Massachusetts General Hospital, USA

${ }^{5}$ Department of Physical Medicine and Rehabilitation, Spaulding Rehabilitation Hospital and Brigham and Women's Hospital, Harvard Medical School, USA

${ }^{6}$ Department of Radiology, Friedrich-Alexander University Erlangen-Nürnberg \& Universitätsklinikum Erlangen, Germany 'Institute of Sports and Exercise Medicine, Department of Surgical Sciences, Faculty of Medicine and Health Sciences, Stellenbosch University, Cape Town, South Africa

${ }^{8}$ Department of Radiology, VA Healthcare System, USA

9 The International Olympic Committee Research Center, South Africa

${ }^{\#}$ Equal Contribution

*Corresponding author: Daichi Hayashi, MD, PhD, Clinical Associate Professor of Radiology, Department of Radiology Stony Brook Medicine, HSc Level 4, Room 120, Stony Brook, NY 11794, USA, Tel: +1-631-444-5400, Fax: +1-631-444-7538

\begin{abstract}
Background: Muscle injuries may affect elite athletes including those competing at the Paralympic Games. We aimed to describe the frequencies, anatomic distribution, and severity of muscle injuries involving Paralympic athletes during the Rio de Janeiro 2016 Summer Paralympic Games.

Methods: Imaging-depicted muscle injuries in Paralympic athletes were identified upon retrospective review of all MRI studies performed at the Games. Images were evaluated retrospectively by five board-certified musculoskeletal radiologists with expertise in sports injuries. We recorded the distribution of muscle injuries by sports discipline, athletes' impairment type, anatomic location and severity of injuries using the modified Peetrons classification and the British Athletics Muscle Injury Classification (BAMIC). Demographic characteristics including impairment type were also analyzed.
\end{abstract}

Results: 4378 para athletes from 160 teams were included. $242 \mathrm{MRI}$ exams were performed and there were $35 \mathrm{MRI}$-depicted muscle injuries in 33 athletes $(73 \%$ male, mean age: 28.7 years - range 20-41). Para athletes from track and field (athletics) disciplines were most commonly affected by muscle injuries ( $\mathrm{N}=23,66 \%$ ), followed by football players $(\mathrm{N}=4,11 \%)$ and power lifters $(\mathrm{N}=4,11 \%)$. The majority of injuries affected lower limb muscles $(\mathrm{N}=28,80 \%)$, with the biceps femoris being the most common $(N=10,29 \%)$. Most frequent injuries were modified Peetrons grade 1 injuries $(\mathrm{N}=15,43 \%)$, and BAMIC grade $2 a$ injuries $(\mathrm{N}=7,20 \%)$.

Conclusion: Muscle injuries in this population were rare. Hamstring muscle injuries were the most common and were observed most frequently in ambulatory para athletes competing in athletics.

\section{Keywords}

Muscle injury, Paralympic, Magnetic resonance imaging, Sport injury, Rio de Janeiro, Imaging 


\section{Introduction}

Muscle injuries adversely affect short- and long-term performance in athletes including those competing in Olympic and Paralympic Games. Knowledge of the pattern of muscle injuries affecting para athletes from various sport disciplines is important for sports physicians and may provide insights for future injury management and prevention initiatives. Injury prevention, diagnosis and management considerations may be different in Olympic versus Paralympic athletes, including reported challenges in imaging studies conducted in Paralympians [1].

Recently there have been several reports describing the epidemiological aspects of sports injuries sustained at the Rio de Janeiro Summer Olympic Games in 2016 including muscle injuries [2-5]. However, to the best of our knowledge, a critical and detailed review of imaging-depicted muscle injuries involving elite athletes with impairment during the summer Paralympic Games has not been described. A retrospective analysis of team-sport wheelchair falls during Rio 2016 Summer Paralympics was recently published [6], but only focused on mechanisms and characteristics of falls and did not analyze any specific injuries such as muscle injuries or fractures. Injury surveillance reports from London 2012 Summer Paralympic Games, Pyeongchang 2018 and Sochi 2014 Winter Paralympic Games have also been published [7-9], although there was no detailed analysis specifically related to muscle injuries. Similarly, themed injury surveillance studies in Paralympic related sports have also been published [10-12], although these studies were not related to any specific Paralympic Games. Despite multiple publications reporting injuries in Paralympic athletes, to the best of our knowledge, a descriptive analysis of MRI-depicted muscle injuries at Paralympic Games has never been reported.

The aim of our study was therefore to describe the incidence, the anatomic distribution, and the severity of MRI-depicted muscle injuries involving Paralympic athletes during the Rio de Janeiro 2016 Summer Paralympic Games. We also assessed whether the athletes' underlying impairment might have contributed to muscle injuries in a pattern unique to Paralympic athletes.

\section{Materials and Methods}

\section{Ethical approval}

An Institutional Review Board (IRB) approval was obtained from Boston University School of Medicine (\#H- 36593). All images were treated with strict confidentiality and in the de-identified fashion during data collection, storage and analysis. IRB waived the need for informed consent due to the fact that all data used in our study were totally anonymized and unidentifiable.

\section{Data acquisition}

All MRI studies that were obtained on para athletes during the Games of 2016 Summer Paralympic in Rio de Janeiro were evaluated for muscle injuries. MR images without intravenous contrast were obtained at the dedicated imaging center for Paralympic Games in Rio de Janeiro using two types of MRI systems (3T Discovery MR750w and 1.5-T Optima $450 \mathrm{MRw}$; both GE Healthcare, Brazil). For assessment of muscle injuries, we used proton density-weighted or T2-weighted sequences with fat suppression in axial, sagittal, and coronal planes, as well as at least one plane of T1weighted sequence for all anatomical locations.

\section{Interpretation and analysis}

Five board-certified musculoskeletal radiologists (all of whom are co-authors) with 3 to 19 years of experience in musculoskeletal imaging independently and retrospectively reviewed all MRIs for the presence and severity of muscle injuries specifically for the purpose of this study. None of the radiologists had access to clinical MRI reports issued by on-site radiologists at the time of image acquisition during Paralympics. Any discrepancies in reading amongst different radiologists were adjudicated by means of consensus agreement by all readers. Names of the injured muscles (e.g. deltoid, biceps femoris, rectus femoris, etc.), in each paraathlete were recorded using a spreadsheet together with detailed demographic characteristics. Acute muscle injuries were defined as the presence of so-called "feathery-pattern" edema-like signal changes within the muscle on T2-weighted or proton density-weighted fat suppressed sequences. On occasions where MRI also showed evidence of scar tissue formation on top of acute muscle injuries as described above, such para athletes were classified to have "acute on chronic" injuries. Some athletes who only had musculotendinous junction scarring without evidence of acute injury were classified to have "chronic" injuries. Para atheletes who developed delayed onset muscle soreness did not fit in any of above categories.

We utilized a modified Peetrons classification system [13] to perform semiquantitative grading of muscle injuries. Grade 1 injury was defined as the presence of edema (ill-defined hyperintensity) on $\mathrm{T} 2$ or proton density weighted fat suppressed sequences with absence of muscle fiber disruption or tearing). Grade 2 was defined as the presence of muscle fiber disruption and partial tearing. Grade 3 was defined as retracted muscle/tendon rupture.

We also assessed the location and severity of injuries using the British Athletics Muscle Injury Classification (BAMIC) which is known to provide correlation between injury severity and estimated recovery time and return to play $[14,15]$. Muscle injuries were graded as follows. Grade $\mathrm{Oa}=$ focal muscle injury with normal MRI; grade 
$\mathrm{Ob}=$ patchy edema-like signal changes throughout one or more muscles; grade 1 = patchy edema-like signal changes that is less than $10 \%$ cross-section, longitudinal length of less than $5 \mathrm{~cm}$, and fiber disruption of less than $1 \mathrm{~cm}$; grade 2 = patchy edema-like signal changes that is between 10 and $50 \%$ cross-section, longitudinal length of $5-15 \mathrm{~cm}$, and fiber disruption of less than $5 \mathrm{~cm}$; grade 3 = patchy edema-like signal changes that is greater than $50 \%$ cross-section, longitudinal length of greater than $15 \mathrm{~cm}$, and fiber disruption of greater than $5 \mathrm{~cm}$. Grades 1-3 are subclassified based on the site of injury; $\mathrm{a}=$ myofascial, $\mathrm{b}=$ myotendinous, $\mathrm{c}=$ tendinous. Grade 4 is defined as complete retracted tear of the muscle (myofascial and myotendinous involvement). For grade 4 , sole tendinous tear is designated as grade 4c.

\section{Classification of para athletes' impairment}

Para athletes' impairment types were categorized as follows - (i) Visual impairment including severe blindness, (ii) Physical impairment due to upper motor neuron disease because of cerebral palsy or traumatic brain injury, (iii) Physical impairment due to upper limb deficiency because of amptation, dysmelia, or congenital deformity, (iv) Physical impairment due to lower limb deficiency, and ( $v$ ) Physical impairment due to impaired muscle power as a result of polio myelitis [16].

\section{Results}

In total, 4378 para athletes from 160 teams were included. $242 \mathrm{MRI}$ exams were performed and found 35 muscle injuries in 33 athletes $(73 \%$ male, mean age: 28.7 years - range 20-41). The most common impairment amongst the athletes with imaging depicted muscle inuries was 'visual impairment' ( $N=17,49 \%)$. The majority of injuries were acute $(\mathrm{N}=27,77 \%)$ and affected muscles of the lower limbs ( $N=28,80 \%)$, with the thigh muscles being the most commonly involved $(N=21,60 \%)$. Details of demographic characteristics relevant to all imaging depicted muscle injuries are summarized in Table 1.

Table 1: Demographics of imaging-depicted muscle injuries in the Rio 2016 Paralympic Games.

\begin{tabular}{|c|c|}
\hline Demographics & $N(\%)$ \\
\hline \multicolumn{2}{|l|}{ Gender (number of athletes) } \\
\hline Male & $24^{*}(73 \%)$ \\
\hline Female & $9^{* *}(27 \%)$ \\
\hline \multicolumn{2}{|l|}{ Impairment (number of injuries) } \\
\hline Visual impairment & $17(49 \%)$ \\
\hline Physical impairment, upper motor neuron injury & $5(14 \%)$ \\
\hline Physical impairment, lower limb deficiency & $6(17 \%)$ \\
\hline Physical impairment, upper limb deficiency & $3(9 \%)$ \\
\hline Impaired muscle power, post polio myelitis & $4(11 \%)$ \\
\hline \multicolumn{2}{|l|}{ Laterality (number of muscle injuries) } \\
\hline Left & $14(40 \%)$ \\
\hline Right & $21(60 \%)$ \\
\hline \multicolumn{2}{|c|}{ Chronicity of muscle injury (number of muscle injuries) } \\
\hline Acute & $27(77 \%)$ \\
\hline Acute on chronic & $3(9 \%)$ \\
\hline Chronic & $2(6 \%)$ \\
\hline Unclassified (Delayed onset muscle soreness) & $3(9 \%)$ \\
\hline \multicolumn{2}{|l|}{ Injury site (number of muscle injuries) } \\
\hline Shoulder & $7(20 \%)$ \\
\hline Hip & $3(9 \%)$ \\
\hline Thigh & $21(60 \%)$ \\
\hline Lower leg & $4(11 \%)$ \\
\hline \multicolumn{2}{|c|}{ Location of injury within muscle (number of muscle injuries) } \\
\hline Proximal third & $14(40 \%)$ \\
\hline Middle third & $12(34 \%)$ \\
\hline Distal third & $8(23 \%)$ \\
\hline Diffuse & $1(3 \%)$ \\
\hline \multicolumn{2}{|l|}{ BAMIC grade (number of muscle injuries) } \\
\hline $0 a, 0 b, 1 a$ & 0 \\
\hline
\end{tabular}




\begin{tabular}{|l|l|}
\hline $1 \mathrm{~b}$ & $5(14 \%)$ \\
\hline $1 \mathrm{c}$ & 0 \\
\hline $2 \mathrm{a}$ & $7(20 \%)$ \\
\hline $2 \mathrm{~b}$ & $4(11 \%)$ \\
\hline $2 \mathrm{c}$ & $2(6 \%)$ \\
\hline $3 \mathrm{a}$ & $5(14 \%)$ \\
\hline $3 \mathrm{~b}$ & 0 \\
\hline $3 \mathrm{c}$ & $4(11 \%)$ \\
\hline 4 & 0 \\
\hline $4 \mathrm{c}$ & $2(6 \%)$ \\
\hline Unclassifiable & $6(17 \%)$ \\
\hline Modified Peetrons grade (number of muscle injuries) & \\
\hline 1 & $15(43 \%)$ \\
\hline 2 & $12(34 \%)$ \\
\hline 3 & $2(6 \%)$ \\
\hline Unclassifiable & $6(17 \%)$ \\
\hline
\end{tabular}

${ }^{*}$ One female athlete had two separate muscle (supraspinatus and deltoid) injuries. ${ }^{* *}$ One male athlete had bilateral deltoid muscle injuries.
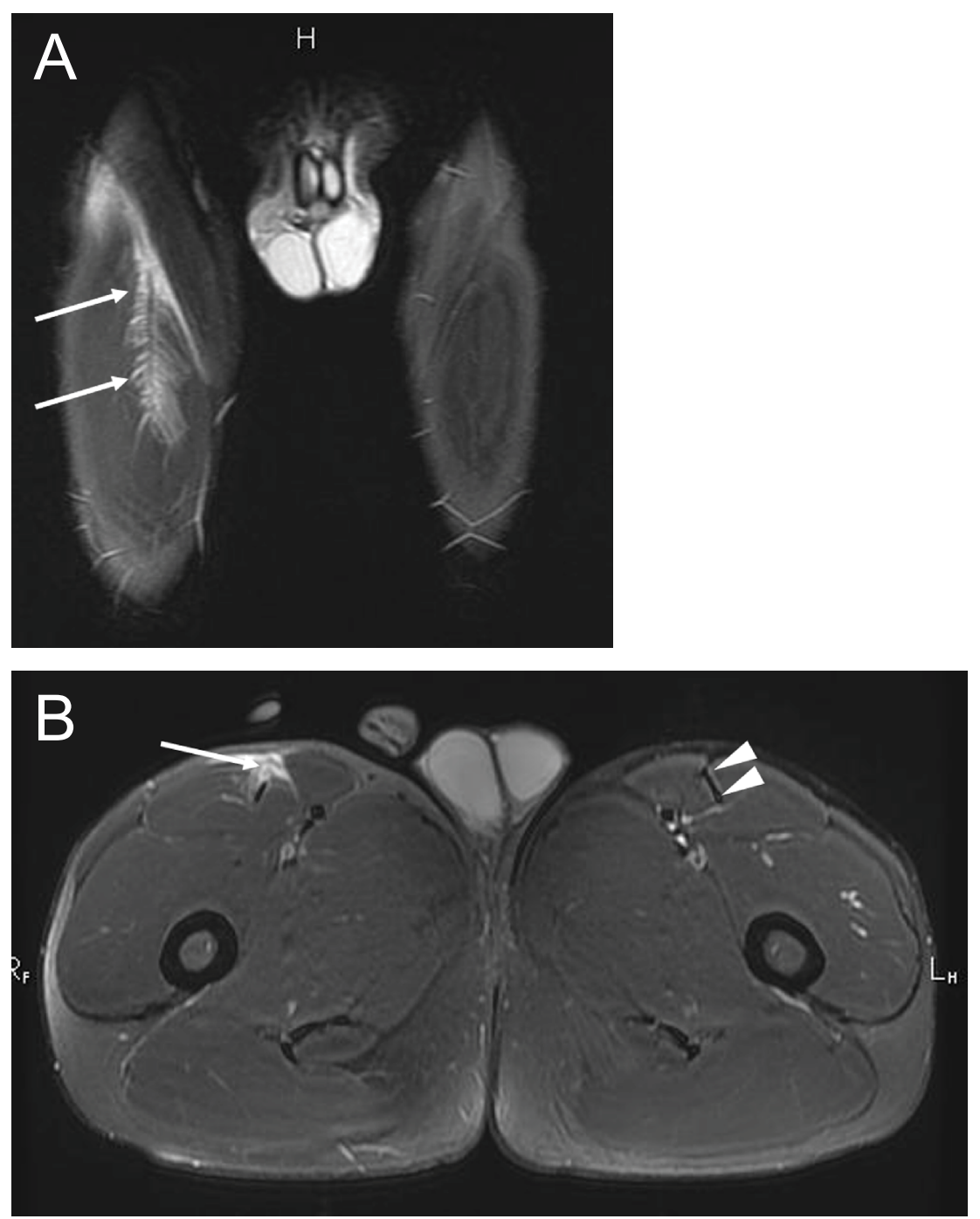

Figure 1: Para athlete participating in short distance sprinting (a) Coronal T2-weighted fat-suppressed image shows illdefined feathery edema (high signal intensity) at the myotendinous junction of the right rectus femoris muscle (arrows); (b) Axial T2-weighted fat-suppressed sequence demonstrates partial rupture of the anterior aspect of the intramuscular tendon (arrow). Note the normal intramuscular tendon at the same anatomical location on the left (arrowheads). This injury was consistent with modified Peetrons grade 2 and BAMIC grade $3 \mathrm{c}$. 
Severity of acute muscle injuries according to the modified Peetrons classification (Table 1)

Most injuries depicted on MRI were grade $1(\mathrm{~N}=15$; $43 \%)$, of which 4 affected the biceps femoris. Twelve muscle injuries were grade 2 (34\%), of which 4 affected the biceps femoris and 3 affected rectus femoris (Figure 1). Two muscle injuries were grade $3(6 \%)$ affecting biceps femoris and rectus femoris. Six injuries did not fit into any of above categories ( 2 cases of chronic musculotendinous junction scarring, one case of incomplete assessment of severity due to signal abnormality extending beyond the field of view, and three cases of delayed onset of muscle soreness with symptoms being observed 48 hours after competition [17]).

\section{Severity of acute muscle injuries according to the British Athletics Muscle Injury system (Table 1)}

In regard to the extent of injuries, grade 2 injuries were most frequent ( 13 cases, $37 \%$ ), followed by grade 3 injuries ( 9 cases, $26 \%$ ). Six injuries could not be classified because of incomplete assessment of severity due to signal abnormality extending beyond the field of view. Myofascial ("a") injuries and tendinous ("c") injuries were most frequently seen in the biceps femoris muscle $(\mathrm{N}=4$, and $\mathrm{N}=5$, respectively), while myotendinous junction ("b") injuries were most commonly found in the semitendinosus and hip adductor muscles $(\mathrm{N}=2)$. The majority of muscle injuries were reported in track and field athletes $(\mathrm{N}=23,66 \%$ of all MRI-depicted muscle injuries), followed by football (including 5 -a-side and 7 -a-side) players $(\mathrm{N}=4,11 \%)$ and powerlifters $(\mathrm{N}=4$, $11 \%)$. Incidence of new MRI-depicted muscles injuries (i.e. acute injuries, acute-on-chronic injuries, and Delayed Onset Muscle Soreness [DOMS]) was low in all disciplines and summarized in Table 2. No such injuries were reported in sport disciplines that are not listed in Table 2.

\section{Distribution of muscle injuries stratified by impairment type (Table 3)}

Approximately half of athletes with muscle injuries were of the visually impaired group which includes

Table 2: Incidence of imaging-depicted muscle injuries during the 2016 Paralympics for each discipline.

\begin{tabular}{|l|l|l|l|}
\hline Disciplines & $\begin{array}{l}\text { Number of athletes participated in } \\
\text { each discipline (N) }\end{array}$ & $\begin{array}{l}\text { Number of imaging-depicted } \\
\text { muscle injuries (n) }\end{array}$ & $\begin{array}{l}\text { Incidence proportion } \\
\text { (n/N) }\end{array}$ \\
\hline Athletics (all types) & 1143 & 21 & $2 \%$ \\
\hline Football & 192 & 4 & $2 \%$ \\
\hline Judo & 131 & 1 & $0.8 \%$ \\
\hline Goalball & 120 & 1 & $0.8 \%$ \\
\hline Rowing & 108 & 1 & $0.9 \%$ \\
\hline Powerlifting & 182 & 4 & $2 \%$ \\
\hline Cycling road & 230 & 1 & $0.4 \%$ \\
\hline
\end{tabular}

Table 3: Number of imaging-depicted muscle injuries stratified by impairment type in the Rio 2016 Paralympic Games.

\begin{tabular}{|c|c|c|c|c|c|}
\hline \multirow[b]{2}{*}{ Muscles } & \multicolumn{5}{|c|}{ Impairment type } \\
\hline & $\begin{array}{l}\text { Visual } \\
\text { impairment }\end{array}$ & $\begin{array}{l}\text { Physical } \\
\text { impairment, upper } \\
\text { motor neuron injury }\end{array}$ & $\begin{array}{l}\text { Physical } \\
\text { impairment, } \\
\text { upper limb } \\
\text { deficiency }\end{array}$ & $\begin{array}{l}\text { Physical } \\
\text { impairment, } \\
\text { lower limb } \\
\text { deficiency }\end{array}$ & $\begin{array}{l}\text { Impaired muscle } \\
\text { power, post } \\
\text { polio myelitis }\end{array}$ \\
\hline Deltoid & 1 & 1 & 0 & 0 & 3 \\
\hline Supraspinatus & 0 & 0 & 0 & 0 & 1 \\
\hline Subscapularis & 1 & 0 & 0 & 0 & 0 \\
\hline Adductor longus/magnus & 2 & 0 & 0 & 0 & 0 \\
\hline Biceps femoris & 5 & 2 & 3 & 0 & 0 \\
\hline Rectus femoris & 1 & 2 & 2 & 0 & 0 \\
\hline Pectineus & 1 & 0 & 0 & 0 & 0 \\
\hline Gluteus maximus & 1 & 0 & 0 & 0 & 0 \\
\hline Gracilis & 0 & 0 & 0 & 1 & 0 \\
\hline Semitendinosus & 1 & 0 & 1 & 1 & 0 \\
\hline Vastus intermedius & 1 & 0 & 0 & 0 & 0 \\
\hline Gastrocnemius Medial head & 2 & 0 & 0 & 0 & 0 \\
\hline Soleus & 1 & 0 & 0 & 0 & 0 \\
\hline Tibialis anterior and extensors & 0 & 0 & 0 & 1 & 0 \\
\hline TOTAL & $17(49 \%)$ & $5(14 \%)$ & $6(17 \%)$ & $3(9 \%)$ & $4(11 \%)$ \\
\hline
\end{tabular}


severe blindness. This impairment category had a wide range of muscle injuries including both upper and lower extremity muscle as summarized in Table 3 . Within this category, the biceps femoris muscle was most commonly injured muscle. Athletes with neurologic physical impairment related to upper motor neuron injury (such as cerebral palsy or sequela of traumatic brain injury) suffered mostly from lower extremity muscle injuries. The only upper extremity injury was seen in a cyclist. In athletes with physical impairment due to upper limb deficiency, only lower limb muscle injuries were seen, all in short distance sprinters. Three lesions were either acute or acute on chronic biceps femoris injuries. In athletes who had physical impairment with lower limb deficiency, only lower limb muscle injuries were observed. Isolated upper extremity muscle injuries were found in powerlifters with impaired muscle power as a result of polio myelitis.

\section{Distribution of muscle injuries in each sport discipline (Table 4)}

The distribution of muscle injuries in each sport discipline depicted using MRI is presented in Table 4. Of the 23 muscle injuries ( 21 acute and 2 chronic) detected in the athletics discipline, the majority of lesions were diagnosed in short distance sprinting $(100 \mathrm{~m}, 200 \mathrm{~m}$, and $400 \mathrm{~m}, \mathrm{~N}=19,2 \%$ incidence). Imaging-depicted muscle injuries in long distance runners $(5000 \mathrm{~m}, 10,000 \mathrm{~m}$, and marathon) and long jumpers were much less frequent ( $N=2$ and $N=2$, respectively). Hamstring injuries were the most common muscle group affected. Quadriceps injuries (all rectus femoris injuries) accounted for 5 injuries (22\%). In other sport disciplines, a total of 12 muscle injuries (of which 9 were acute) were detected. The majority of lesions were diagnosed in football players ( $N=4,33 \%$ of 12 injuries) and power lifters ( $N$ $=4,33 \%$ ). Three of 4 injuries in football players were lower extremity muscles and one injury affected upper extremity. All 4 injuries of powerlifters were from upper extremity.

\section{Discussion}

To the best of our knowledge, this study represents the first report of imaging-diagnosed muscle injuries in a cohort of elite Paralympic athletes. Overall incidence proportion was very low, ranging between 0 and $2 \%$ of athletes from all disciplines of sports. Characteristic injury patterns were observed in certain categories of athletes. Only lower limb muscle injuries were observed in athletes with upper or lower limb deficiencies. Conversely, only upper limb muscle injuries were found in powerlifters who had impaired muscle power related to polio myelitis with no or very limited use of their lower limbs. Almost half of all athletes affected by MRI depicted muscle injuries had visual impairment and this category of athletes who were ambulatory had variety of upper and lower limb muscle injuries overall.

When compared to muscle injury data from Rio 2016 Summer Olympic Games, similarities with the current study include a relatively high proportion of muscle injuries affecting biceps femoris and rectus femoris muscles (total 31 of 81 muscle injuries [38\%] in Olympics; 15 of 35 muscle injuries [43\%] in Paralympics) [2]. Short distance sprinting was the discipline with highest incidence of muscle injuries in both Games ( 25 of 81 [31\%] in Olympics and 19 of 35 [54\%] in Paralympics)

Table 4: Number of imaging-depicted muscle injuries stratified by types of sport.

\begin{tabular}{|c|c|c|c|c|c|c|c|}
\hline \multirow[b]{2}{*}{ Muscles } & \multicolumn{7}{|c|}{ Types of sport } \\
\hline & Athletics $^{*}$ & Football $^{* *}$ & Judo & Goalball & Rowing & Power lifting & Cycling road \\
\hline Deltoid & 0 & 0 & 1 & 0 & 0 & 3 & 1 \\
\hline Supraspinatus & 0 & 0 & 0 & 0 & 0 & 1 & 0 \\
\hline Subscapularis & 0 & 1 & 0 & 0 & 0 & 0 & 0 \\
\hline Gluteus maximus & 1 & 0 & 0 & 0 & 0 & 0 & 0 \\
\hline Adductor longus/magnus & 1 & 0 & 0 & 1 & 0 & 0 & 0 \\
\hline Gracilis & 1 & 0 & 0 & 0 & 0 & 0 & 0 \\
\hline Pectineus & 1 & 0 & 0 & 0 & 0 & 0 & 0 \\
\hline Biceps femoris & 9 & 1 & 0 & 0 & 0 & 0 & 0 \\
\hline Semitendinosus & 3 & 0 & 0 & 0 & 0 & 0 & 0 \\
\hline Rectus femoris & 5 & 0 & 0 & 0 & 0 & 0 & 0 \\
\hline Vastus intermedius & 0 & 1 & 0 & 0 & 0 & 0 & 0 \\
\hline Gastrocnemius medial head & 1 & 1 & 0 & 0 & 0 & 0 & 0 \\
\hline Soleus & 1 & 0 & 0 & 0 & 0 & 0 & 0 \\
\hline Tibialis anterior \& extensors & 0 & 0 & 0 & 0 & 1 & 0 & 0 \\
\hline TOTAL & $23(66 \%)$ & $4(11 \%)$ & $1(3 \%)$ & $1(3 \%)$ & $1(3 \%)$ & $4(11 \%)$ & $1(3 \%)$ \\
\hline
\end{tabular}

*Athletics discipline included short distance running, long distance running, and long jump; ** Football includes 5-a-side and 7-a-side 
[2]. The overall incidence of acute muscle injuries in the Olympics was also very low and the highest incidence of $2 \%$ was seen in the rhythmic gymnastics discipline when stratified according to sport type [2].

In contrast, the only muscle injuries sustained by cyclists during the Olympics were lower extremity muscles. However, the only muscle injured in Paralympic cyclist was upper extremity muscle. This Paralympian cyclist had 'C4' classification for impairment by International Paralympic Committee definition [16], which means the athlete had second least severe lower limb impairment (i.e. in cycling, C1 is most severe impairment and C5 is least severe) but was still able to ride a standard bicycle. Exact circumstance of injury is unknown, however, and the fact that this Paralympic cyclist injured upper limb muscle rather than lower limb muscle may been due to an injury outside of training or competition, since the athlete was riding a bike using legs, rather than a handcycle which is driven using upper limbs. Powerlifting is open to athletes who have impairment in their lower limbs or hips, which would prohibit them from competing in able-bodied (standing) weightlifting [16]. Therefore, athletes compete in bench press in powerlifting. It is therefore expected that all 4 muscle injuries reported in the current study involved upper extremity muscles. In contrast, during 2016 Olympic Games, all muscle injuries reported in weightlifters involved lower extremity muscles (5 injuries affecting biceps femoris, gluteus maximus, and vastus lateralis) [2].

No acute muscle injury was reported in rowers in either the Paralympics or Olympics. Only one nonacute lower extremity muscle injury was reported in the current study in a rower, who was classified as 'LTA-PD' which means the athlete had a physical impairment but could use their legs, trunk and arms to accelerate the boat and can use the sliding seat [16]. The ankle extensor compartment injury (delayed onset muscle soreness) was thus likely from the use of legs to row the boat in an athlete who had a lower limb deficiency. However, exact severity of lower limb deficiency or if the injury was on the same side as the deficient limb is unknown.

Muscle injuries reported in a judo athlete, a goalball player, and 3 football players may not be directly related to the type of impairment, since all these athletes had visual impairment and no specific limb-related or neurological impairment. Only one football player had physical impairment related to co-ordination and balance difficulties in all four limbs and trunk due to ataxia or athetosis (IPC classification 'FT6'. i.e. FT5 is most severe and FT8 is least severe impairment). FT6 players typically have difficulties in dribbling the ball when running, accelerating, and stopping [16]. This footballer had a biceps femoris injury, for which underlying lowerlimb related impairment could have been a predisposing factor. However, the biceps femoris injury was the most common acute muscle injury in footballers during 2016 Olympic Games (3 injuries) [2], so this muscle injury may be characteristic to the football itself, regardless of physical impairment. Finally, all muscle injuries in athletics discipline affected only lower limbs in both Paralympic and Olympic games, and biceps femoris and rectus femoris were the two most commonly injured muscles. Thus, injury patterns in athletics discipline seem similar regardless of the presence of any physical impairment.

It is difficult to directly compare our data specific to MRI-depicted muscle injuries to available prior publications which generally reported all types of injuries and not just muscle injuries in Paralympic athletes. However, with this limitation in mind, it has been reported that lower extremity injuries (including muscle injuries) are more common in ambulatory Paralympic athletes (visually impaired, amputee, cerebral palsy) and upper extremity injuries are more frequent in athletes who use a wheelchair [18], which is not surprising given the nature of Paralympic sports. More specifically, during Summer 2012 London Paralympic Games, the most common injuries occurred to the thigh in ambulant athletes (16.4\% of all injuries; Incidence Rate [IR], 4.0 injuries per 1000-athlete days), most common injury sites in wheelchair or seated athletes was the shoulder/clavicle (19.3\% of all injuries; IR, 3.4) [7]. Our data also showed similar injury patterns and are thus in line with the existing literature evidence. Descriptive epidemiological studies of all types of injuries (including fractures, contusion, abrasion, strain, sprain, etc...) affecting both Summer and Winter Paralympic athletes have been published [8,9,19-22], however to the best of authors knowledge no prior study has specifically performed comprehensive analyses focusing on imaging-depicted muscle injuries, and thus no direct comparison with the data from our study is possible. In-depth analysis of fall injuries affecting Paralympic athletes playing wheelchair team sports was recently published [6], but our study did not include any muscle injuries occurring in athletes using wheelchairs.

Limitations of this study include lack of information regarding the exact circumstance and mechanism of muscle injuries, as well as lack of clinical information including post-injury recovery and return to play. Thus, we do not know how MRI based grading of muscle injuries analyzed in our study actually affected or changed each injured para athlete's management/therapy. We only assessed those injuries that underwent MRI and cannot exclude that some minor injuries were not evaluated by MRI and thus, missed in our analysis. There may be some athletes who had clinically diagnosed muscle injuries but did not have MRI to confirm such injury on imaging, thereby putting them outside the scope of our study. However, since imaging was readily available during the Games, it is likely that the majority of elite para athletes had imaging assessment in clinically suspected muscle 
injuries, especially in a major sport event such as the Paralympics.

\section{Conclusion}

Our study showed that MRI-depicted muscle injuries were rare in Paralympic athletes during the Rio 2016 Summer Paralympic Games. Hamstring muscle injuries were the most common and were observed most frequently in para athletes competing in the sport of athletics. MRI-depicted muscle injuries correlated with impairment type - a pattern that was seen in broader para athlete injury epidemiological studies. MRI played a major role for detection and radiological severity assessment of muscle injuries in athletes during the 2016 Paralympic Games. Paralympic athletes and their coaches as well as Paralympic sports organizations may use these data to identify muscles that are particularly at risk in certain disciplines of Paralympic sports, which may in turn help sports physicians institute appropriate injury prevention strategies and optimally manage injured atheltes with impairment.

\section{Ethics Approval}

An Institutional Review Board (IRB) approval was obtained from Boston University School of Medicine (\#H- 36593).

\section{Declaration of Competing Interest}

Ali Guermazi is the President of Boston Imaging Core Lab (BICL), LLC, and a Consultant to MerckSerono, AstraZeneca, Pfizer, Galapagos, Roche and TissueGene. Frank Roemer and Michel Crema are shareholders of BICL, LLC. Frank Roemer is consultant to Calibr California Institute of Biomedical Research. Other authors have nothing to disclose.

\section{Acknowledgements}

We would like to thank Ling Li for performing statistical analysis of the data presented in this manuscript.

\section{Funding Information}

This research did not receive any specific grant from funding agencies in the public, commercial, or not-forprofit sectors.

\section{References}

1. Bethapudi S, Campbell RSD (2018) Challenges of imaging injured Paralympic Athletes. Eur J Radiol 108: 283-287.

2. Crema MD, Jarraya M, Engebretsen L, Roemer FW, Hayashi D, et al. (2018) Imaging-detected acute muscle injuries in athletes participating in the Rio de Janeiro 2016 Summer Olympic Games. Br J Sports Med 52: 460-464.

3. Hayashi D, Jarraya M, Engebretsen L, Crema MD, Roemer FW, et al. (2018) Epidemiology of imagingdetected bone stress injuries in athletes participating in the Rio de Janeiro 2016 Summer Olympics. Br J Sports Med 52: 470-474.

4. Heiss R, Guermazi A, Jarraya M, Engebretsen L, Roemer
FW (2018) The epidemiology of MRI-detected pelvic injuries in athletes in the Rio de Janeiro 2016 Summer Olympics. Eur J Radiol 105: 56-64.

5. Jarraya M, Crema MD, Engebretsen L, Teytelboym OM, Hayashi D, et al. (2018) Epidemiology of imagingdetected tendon abnormalities in athletes participating in the Rio de Janeiro 2016 Summer Olympics. Br J Sports Med 52: 465-469.

6. Sasadai J, Maeda N, Shimizu R, Kobayashi T, Sakai S, et al. (2020) Analysis of team-sport wheelchair falls during the Rio 2016 Summer Paralympic Games: A video-based crosssectional observational study. BMJ Open 10: e033088.

7. Blauwet CA, Cushman D, Emery C, Willick SE, Webborn N, et al. (2016) Risk of Injuries in Paralympic Track and Field Differs by Impairment and Event Discipline: A Prospective Cohort Study at the London 2012 Paralympic Games. Am J Sports Med 44: 1455-1462.

8. Derman W, Runciman P, Jordaan E, Schwellnus M, Blauwet C, et al. (2020) High incidence of injuries at the Pyeongchang 2018 Paralympic Winter Games: A prospective cohort study of 6804 athlete days. Br J Sports Med 54: 38-43.

9. Derman W, Schwellnus MP, Jordaan E, Runciman P, de Vliet PV, et al. (2016) High incidence of injury at the Sochi 2014 Winter Paralympic Games: A prospective cohort study of 6564 athlete days. Br J Sports Med 50: 1069-1074.

10. Heneghan NR, Heathcote L, Martin P, Spencer S, Rushton A (2020) Injury surveillance in elite Paralympic athletes with limb deficiency: A retrospective analysis of upper quadrant injuries. BMC Sports Sci Med Rehabil 12: 36.

11. Hollander K, Kluge S, Glöer F, Riepenhof $H$, Zech $A$, et al. (2020) Epidemiology of injuries during the Wheelchair Basketball World Championships 2018: A prospective cohort study. Scand J Med Sci Sports 30: 199-207.

12. Zwierzchowska A, Rosołek B, Celebańska D, Gawlik K, Wójcik M (2020) The Prevalence of Injuries and Traumas in Elite Goalball Players. Int J Environ Res Public Health 17: 2496.

13. Ekstrand J, Healy JC, Walden M, Lee JC, English B, et al. (2012) Hamstring muscle injuries in professional football: The correlation of MRI findings with return to play. $\mathrm{Br} J$ Sports Med 46: 112-117.

14. Pollock N, James SL, Lee JC, Chakraverty R (2014) British athletics muscle injury classification: A new grading system. Br J Sports Med 48: 1347-1351.

15. Pollock N, Patel A, Chakraverty J, Suokas A, James SLJ, et al. (2016) Time to return to full training is delayed and recurrence rate is higher in intratendinous (' $c$ ') acute hamstring injury in elite track and field athletes: clinical application of the British Athletics Muscle Injury Classification. Br J Sports Med 50: 305-310.

16. International Paralympic Committee (2015) Explanatory guide to Paralympic classification. Paralympic summer sports.

17. Hotfiel T, Freiwald J, Hoppe MW, Lutter C, Forst R, et al. (2018) Advances in Delayed-Onset Muscle Soreness (DOMS): Part I: Pathogenesis and Diagnostics. Sportverletz Sportschaden 32: 243-250.

18. Ferrara MS, Peterson CL (2000) Injuries to athletes with disabilities: Identifying injury patterns. Sports Med 30: 137143.

19. Derman W, Runciman P, Schwellnus M, Jordaan E, Blauwet C, et al. (2018) High precompetition injury rate dominates the 
injury profile at the Rio 2016 Summer Paralympic Games: A prospective cohort study of 51198 athlete days. Br J Sports Med 52: 24-31.

20. Derman W, Schwellnus M, Jordaan E, Blauwet CA, Emery C, et al. (2013) Illness and injury in athletes during the competition period at the London 2012 Paralympic Games: Development and implementation of a web-based surveillance system (WEB-IISS) for team medical staff. Br J Sports Med 47: 420-425.
21. Webborn N, Willick S, Emery CA (2012) The injury experience at the 2010 winter Paralympic games. Clin J Sport Med 22: 3-9.

22. Willick SE, Webborn N, Emery C, Blauwet CA, PitGrosheide, et al. (2013) The epidemiology of injuries at the London 2012 Paralympic Games. Br J Sports Med 47: 426432. 